\title{
Relating to Place
}

\author{
JENANNE FERGUSON
}

$\mathrm{T}$ he three articles that comprise this issue of Sibirica engage with the complexities of dialogic relationships to place. What do people bring to a place? What does place catalyze for people? The authors come from diverse disciplinary backgrounds and bring disparate frameworks from human geography, cultural anthropology, and philosophy; in each article, they engage with both the immediate present and the broader arc of time and reflect on the pragmatic and practical dimensions of relationships with a place to those more spiritual and ineffable.

The first article in this issue approaches the relationship to place through that of legal structures and evolution of Indigenous rights in Russia's Far Northeast. Nicholas Parlato and his coauthors Gail Fondahl, Viktoriya Filippova, and Antonina Savvinova look at the territories of traditional nature use (TTPs), as these are realized within the Republic of Sakha (Iakutiia). Found across the Russian Federation, these legal territorial legal formations have been influenced by the intersections of regional and federal policies as they have unfolded in particular regions and republics. For indigenous northerners in the Sakha Republic, TTPs have been a key instrument for asserting indigenous rights and solidarity in relation to land stewardship and lifeways. However, the specific political moment in which the TTPs were each created-as well as the particulars of the land itself-have led to striking differences in what these places have come to be for their Indigenous inhabitants. The Bellet Evenk National Nasleg and the Anamy National Nasleg, both primarily home to Evenki people and located in the Aldan District in the south of the republic, were formed just eight years apart, in 2008 and 2016, respectively. However, in intervening years there were numerous legal reforms that led to different processes and outcomes; the authors deftly describe how these particular changes had impacts on Anamy's development in contrast with that of Bellet. They discuss the nature of the relationships between the TTPs and other places in the Republic and Russia more broadly: Yakutsk and the regional Sakha Republic administration and that of Moscow and the federal power apparatus. Although the TTPs are "sites of legal-territorial experimentation, where 
local and Republican-level leadership used the tools available to build common cause and protect their interests against the powerful national executive," changing relations with the Russian federal government and new state laws coming into play these TTPs are in a state of potential flux.

Next, Vasilina Orlova also looks at a place in flux, this time a small local road in Irkutsk oblast. Orlova's article, a poetic exploration of a road that is both a (faulty) connector and a place in and of itself, captures people in dialogue with place. Her piece, which evocatively describes the tumultuous relationship that the people of Anosovo village have with their ruined, razbitaia doroga (broken road), reminds us that even malfunctioning places and structures are still productive. They are powerful catalysts and also media through which affect can traveldeeply tied to both past and present, even as ruins they are sources of possibility. While humans impose their imaginations and presence on the infrastructure they create, in turn those roads and buildings can foster affective transformation-here, helping in producing various social feelings and senses of belonging even as they hinder and frustrate the locals as they travel. In dialogue with both affect theory as well as discussions of roads, these feelings of attachment may seem contradictory, but Orlova's theorizing, interwoven with vignettes about life with—and on—the broken road, helps the reader to understand one of her central questions: "what keeps people living in the conditions of dwindling economic possibilities, what defines mobility, and how people 'belong' to a place and place belongs to them."

This question of belonging to a place-and place also belonging to people-leads us to Francesc Bellaubi's article. Although Bellaubi does not evoke the same discussion of affective infrastructure and its power, his article about Lake Turgoyak, a small, clear lake in the southern Urals, asks some similar philosophical questions through a geoethics framework. The lake is a nexus that highlights the relationships between humans and nature, in which a tangle of oft-contradictory actions and moral responsibilities emerge-and possibilities for better humanenvironmental relations arise. Geoethical questions center on how we might (and do) act as humans in our embedded relationship with the biosphere; how do actions and practices both produce-and underlie-our moral approach to the world in which we live? Interestingly, a foundational thinker who solidified ideas about the biosphere was the geochemist and mineralogist Vladimir Vernadsky, a Russian; together with the Jesuit priest Pierre Teilhard de Chardin, he contributed to early conceptualizations of the noosphere ("the world transformed by the 
energy of human culture"). While Bellaubi's foundational literature is quite different than that of many Siberianists and anthropologists working in Russia, this work that he cites focuses on the relations and connections between all beings in the biosphere is preoccupied with many of the same concerns held by anthropologists theorizing the relationship between humans and other-than-human beings and, trying to reflect the indigenous systems of knowledge that also focus on the indivisibility of human relationships with the land.

A focus on the intrinsic connection to place is essentially what is at the heart of the three articles in this issue of the journal. Whether through discussions of protecting places, as in Parlato et al. and Bellaubi's articles, or navigating the often-frustrating encounters with troublesome structures in Orlova's, we see three glimpses of the ways in which Siberians navigate the powerful relationships with the places in which they live. 